\title{
Pediatrik hastalarda distal radius ve ulna kırıklarının tanı ve tedavisi
}

\section{The diagnosis and treatment of distal radius and ulna fractures in pediatric patients}

\author{
Baki Volkan Çetin ${ }^{1}$, Mehmet Akif Altay ${ }^{2}$, Baran Sarıkaya² \\ ${ }^{1}$ Ceylanpınar Devlet Hastanesi, Ortopedi ve Travmatoloji Bölümü, Şanlıurfa \\ ${ }^{2}$ Harran Üniversitesi Tıp Fakültesi, Ortopedi ve Travmatoloji Anabilim Dalı, Şanlıurfa
}

Distal radius ve ulna kırıkları çocuk ve adolesan yaş grubunda oldukça sık izlenir. Bu kırıklara yaklaşımda, ilgili ekstremitenin nörovasküler durumu, yumuşak doku yaralanmasının varlığı ve en önemlisi radius ve ulnanın fiziyel yaralanmasının olup olmadığının ortaya konulması önemli noktalardır. Bu kırıkların tedavisi, basit redüksiyon ve alçı uygulamasından, acil redüksiyon ve cerrahi tespite kadar değişebilir. Başlangıçta uygulanan tedavi ne olursa olsun ortopedi hekiminin en dikkatli olması gereken nokta, tedavi sonuçlarını etkileyebilecek erken veya geç dönemde oluşabilecek komplikasyonlardır. Bu komplikasyonlar arasında; fizis kırıklarının sonucu olan büyümenin duraklaması, akut kompartman sendromu, yanlış kaynama (malunion) gibi özel dikkat ve takip gerektiren durumlar sayılabilir. Hasta ve ailesi hızlıca günlük aktivitelerine dönmek isterler. Bununla beraber, ekstremitenin uzun dönem fonksiyonelliğini kazanması için yeterli tedaviyi alması şarttır. Ortopedi hekiminin bir diğer önemli görevi de bu ikisi arasındaki dengeyi sağlamaktır. Birçok çalışma, özel kırık tiplerine göre uygun tedavi metodlarını tartışmaktadır. Klinisyenler arasında bu tür kırıklara yaklaşım konusunda anlamlı farklılıklar bulunmaktadır. Bu yazı pediatrik distal önkol kırıklarına yaklaşımla beraber olası komplikasyonlara dikkat çekmek ve güncel literatür bilgileri ışığında derlemeyi amaçlamaktadır.

Anahtar sözcükler: pediatrik; distal radius; önkol kırı̆̆ı
Distal radius and ulna fractures are quite common in children and adolescents. In the approach to these fractures, the neurovascular status of the related extremity, presence of soft tissue injury, and most importantly, the presence of physis injury of the radius and ulna should be clarified. The treatment of these fractures may vary from simple reduction and cast immobilisation to urgent reduction and surgical fixation. Regardless of the initial treatment, the most important point for orthopedic surgeon is early or late complications which may affect the treatment results. These complications include growth arrest which is the result of physis fractures, acute compartment syndrome, malunion which are requiring special attention and follow-up. The patient and parents want to return to their daily activities quickly. However, it is essential for the limb to receive adequate treatment to achieve long-term functionality. Another important task of the orthopedic surgeon is to balance of these two demands. Many studies discuss appropriate treatment modalities for specific types of fractures. There are significant differences between clinicians in their approach to such fractures. This paper aims to draw attention to the management of pediatric distal forearm fractures and possible complications together in the light of the current literature.

Key words: pediatric; distal radius; forearm fracture

\section{Epidemiyoloji}

Distal radius ve ulna kırıkları çocukluk çağında en sık izlenen kırıklardır. Tüm pediatrik kırıkların \%19,935,8'ini oluşturur. Çoğunlukla kapalı redüksiyon ve alçılama ile tedavi edilir. ${ }^{[1]}$ Olguların yarısından biraz fazlası (\%53) nondominant ekstremiteyi etkilemektedir. Kırıkların izlendiği yaş grubu kız çocuklarda 9,3 yıl erkek çocuklarda 10,4 yıldır. Daha çok erkek çocuklarda görülür. Erkek/kız oranı 3/2' dir. ${ }^{[2,3]}$

\section{Anatomi}

Anatomik açıdan önemli noktalar, distal radyoulnar eklem yüzeyi ve önkolun yumuşak doku örtünmesidir. Distal radiusun sekonder kemikleşmesi ilk

- Illetişim adresi: Uzm. Dr. Baki Volkan Çetin, Ceylanpınar Devlet Hastanesi, Ortopedi ve Travmatoloji Bölümü, Şanlıurfa Tel: 0541 - 3172302 e-posta: bvolkanc1@gmail.com

- Geliș tarihi: 2 Subat $2019 \quad$ Kabul tarihi: 2 Subat 2019 
yaş civarı gözlenir ve distal ulnar kemikleşme merkezi ise 5-7 yaşında ortaya çıkar. Radius büyümesinin \%75-80'i distal radyal fizisten kaynaklanır. Devam eden hızlı büyüme nedeniyle distal metafiz zayıf olduğu için bu bölgeden kırıklar daha sık olur. Distal radyoulnar eklem, radiusun ulna etrafinda pronasyon/supinasyon hareketlerini yapmasında en önemli faktördür. Distal radyoulnar eklem birçok komponentten oluşur. Bunlar triangular fibrokartilaj kompleksi (TFK), ulnar kollateral bağ, volar ve dorsal radyokarpal ve radyoulnar bağlar ve pronator kuadratus kasıdır. Bunlar içinde en önemlisi TFK'dir. TFK, distal radyoulnar eklemi rotasyon sırasında maruz kaldığı torsiyonel strese karşı stabilize eder. Distal önkol kırıklarının sıklığına ve deplasmanın da oldukça sık görülmesine rağmen nörovasküler yaralanma sık görülmez. Bunun nedeni pronator kuadratus kasının volar nörovasküler yapıları korumasıdır. Bununla beraber, özellikle açık kırıklarda median ve ulnar sinir yaralanması meydana gelebilir.

\section{Yaralanma Mekanizması}

Distal önkol kırıkları genellikle açık el üzerine düşme sonucu meydana gelir. Eğer el bileği ekstansiyonda ise sıklıkla olduğu gibi distal parça dorsale, fleksiyonda ise volare doğru deplase olur. Torus kırıkları ve minimal deplase kırıklar düşük enerjili yaralanmalar sonucu ortaya çıkarken, deplase kırıklar yüksekten düşme veya öne doğru yüklenmelerle meydana gelir (koşma, bisiklet sürme sırasında olan düşmeler gibi).

\section{Sınıflama}

Distal önkol kırıkları; torus, yeşil ağaç, metafiz, fizis ve Galeazzi kırıkları olarak sınıflanabilir. Metafiziyel kırıklar, deplase ve nondeplase olarak ayrıca sınıflandırılabilir. Bunlar eğer deplase ise deplasmanın yönü ve derecesine göre ayrılır. Fiziyel kırıklar ise genellikle Salter-Harris $(\mathrm{SH})$ sistemine göre sınıflandırılır. Peterson, bu sınıflamaya ek olarak transvers metafiziyel ve fizise longitudinal uzanım gösteren kırık tipini tanımlamıştır. ${ }^{[4]}$ Bu zararsız gibi görülen kırık tiplerinde büyümenin durması görülebileceğinden, dikkatlice tanımlanması gerekir. Galeazzi kırıkları çocuklarda nadir görülür.

\section{Klinik Değerlendirme}

Illk dikkat edilecek en önemli noktalar; yumuşak dokunun durumu ve nörovasküler değerlendirmedir. Yaralanmanın olduğu alan, abrazyon, laserasyon ve açık kırık olasılığı açısından muayene edilir. Yumuşak dokularda şişlik beklenen bir bulgu olsa da, özellikle gelişebilecek kompartman sendromu açısından uyanık olunmalıdır. Muayene etmenin zor olduğu bu hasta grubunda, kompartman sendromunu değerlendirmek kolay olmayacaktır. Bu yüzden, sık aralarla muayene tekrarlanmalıdır. Ana semptom ve bulgular; ajite ruh hali, özellikle durumla orantısız bir şekilde avutulamayan anksiyete ve gittikçe artan analjezi ihtiyacı hekimi uyarmalıdır. Distal ekstremite perfüzyonu, radyal arter nabzının muayenesi, kapiller dolum ve parmakların ısısına bakarak değerlendirilir. Nörolojik değerlendirmede; yapılabildiği ölçüde radyal, ulnar ve median sinirlerin duyu dağılım alanları muayene edilir. Motor fonksiyonları değerlendirmek oldukça güç olacaktır. Bir diğer önemli nokta da, çocuğun başka yaralanması varsa bunun gözden kaçırılmamasıdır. Çünkü, çocuk en çok ağrıyan yeriyle ilgileneceğinden, diğer yaralanmalar atlanabilir. Beraber görülen en sık yaralanmalar, distalde skafoid veya diğer karpal kırıklar ve proksimalde suprakondiler humerus kırıklarıdır (Şekil 1).

Geleneksel düz radyografiler, pediatrik önkol kırıklarının değerlendirilmesi için yeterlidir. Ancak, filmlerin el bileği ve dirsek eklemlerini içine alacak şekilde uygun çekilmiş ön-arka ve yan grafiler olması gerekir.

\section{METAFIZIYEL KIRIKLAR}

\section{Torus Kırıkları}

Tek korteksi içine alan, açık el üzerine düşmeyle oluşan metafiziyel kırıklardır. Genellikle dorsal korteks kompresyona, volar korteks gerilmeye maruz kalır. Volar korteksin sağlam olması nedeniyle bu kırıklar stabil kırıklardır. Anlamlı şişlik ve deformite izlenmez. Distal radius metafizinde nokta hassasiyeti tanıyı doğrular. Torus kırıkları, üç haftalık kısa kol atel veya alçıyla tedavi edilir. Çalışmalar, alçı uygulamasının şart olmadığını elastik bandaj veya atel uygulamasının bu tür kırıkların tedavisinde yeterli olduğunu göstermiştir. ${ }^{[5,6]}$ Torus kırıklarındaki en önemli nokta tanının kesin olmasıdır. Fizisi içine alan kırıklarda (Peterson Tip 1 fiziyel yaralanması) büyümenin durması gelişebilir. Bu tür hastalarda 6-12 ay boyunca büyümenin devam edip etmediği izlenmelidir. ${ }^{[7]}$

\section{Yeşil Ağaç Kırıkları}

Kompresyon tarafinda plastik deformasyon ve gerilim tarafındaki kortekste kırığın izlendiği inkomplet kırık tipidir. Bu kırık, kompresyon ve rotasyon sonucu meydana gelir. Distal 1/3 önkol yeşil ağaç kırıkları genellikle apeks-volar angülasyon ve supinasyon yaralanması olarak karşımıza çıkar. Yeşil ağaç kırıkları, genellikle basit kapalı redüksiyon ve uzun kol alçı ile tedavi edilir. Acil serviste uygulanacak analjezi ve sedasyon yardımıyla kapalı redüksiyon yapılır. Redüksiyon manevrası, deformasyon kuvvetlerinin 

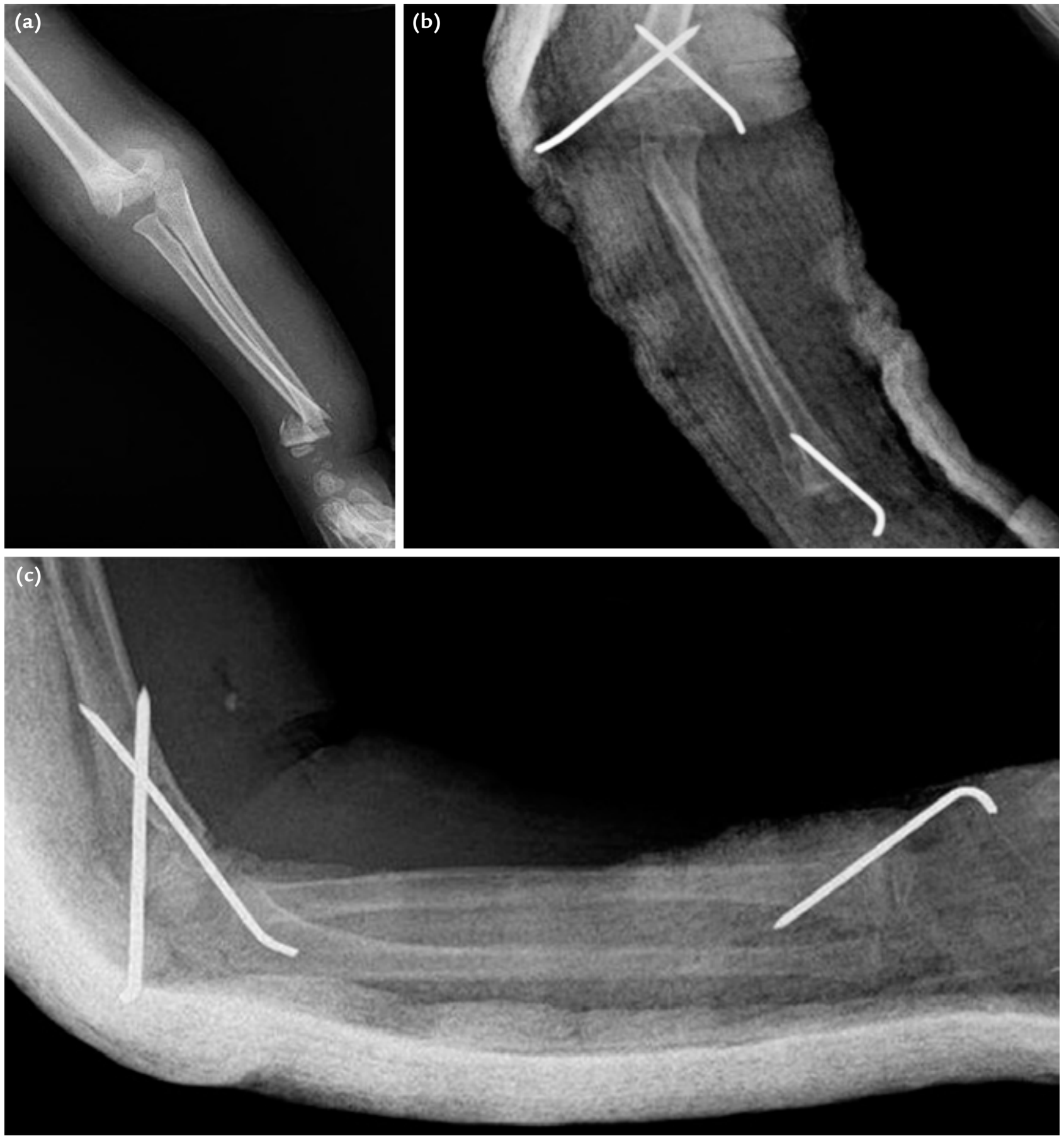

Şekil 1. a-c. Beş yaşında erkek hastanın radius distal uç ve ipsilateral suprakondiler kırığının, ameliyat öncesi ve sonrası radyografik görüntüleri. (Harran Üniversitesi Araştırma ve Uygulama Hastanesi arşivinden)

aksi yönünde uygulanır ve önkol pronasyonda immobilize edilir. Apeks-dorsal angülasyonu olan ve pronasyon yaralanması ile oluşan kırık tipinde ise önkol supinasyonda immobilize edilir. Hastalar genellikle redüksiyondan 1-2 hafta sonra redüksiyonun devamı açısından kontrol edilir. Tekrar kırık riski yüksek olduğundan genellikle bu tür kırıklarda uygulanan uzun kol alçı altı hafta kadar tutulur ve aile, alçının çıkarılması durumunda tekrar kırık riski olduğu konusunda bilgilendirilmelidir. 


\section{Bikortikal Kırıklar}

\section{Nondeplase kırıklar}

Bikortikal veya komplet distal radius metafiz kırıkları, torus kırıklarından daha yüksek enerjili yaralanmalarla oluşur. Eğer açık el üzerine düşme sırasında maruz kalınan aksiyel yüklenmeye torsiyonel kuvvet de eklenirse, distal radius kırığına distal ulna yaralanması da eşlik edebilir. Bu tür kırıkta hasta, el bileğinde ağrı ve şişlikle başvurur. Muayenede, distal radius palpasyonla hassastır. Distal ulna kırığının eşlik ettiği durumda ise TFK, ulnar metafiz ve stiloid hassas ve ağrılı olacaktır. Ağrıya bağlı olarak, önkolun supinasyon ve pronasyonu ve el bileği fleksiyon ve ekstansiyonu kısitlıdır. Radyografide, metafizde transvers uzanan kırık hattı izlenir. Genellikle, kısa veya uzun kol alçıyla en az dört hafta immobilize edilerek tedavi edilir. Birçok çalışmada, iyi şekilde biçimlendirilmiş kısa kol alçıların, redüksiyonun devamında uzun kol alçılar kadar efektif olduğu gösterilmiştir. ${ }^{[8,9]}$ Radyolojik kontroller, ilk karşılaşmadan 7-10 gün sonra redüksiyon kontrolü için yapılır. Yaralanmadan 4-6 hafta sonra alçı uygulaması sonlandırılır. Yeterli kaynama, muayene ve tekrarlı radyografilerle kontrol edilir. Alçı sonrası eklem hareketleri ve güçlendirici egzersizler önerilir. Fizik tedavi genellikle gerekmez. Hasta, 8-10 hafta sonra spor aktivitelerine katılabilir.

\section{Deplase kırıklar}

Distal radius metafizinin deplase kırıklarında hasta, tipik olarak el bileğinde deformite ile gelir. Abrazyon, laserasyon veya açık kırığa ait bulgular bulunabilir. Redüksiyon öncesi mutlaka nörovasküler muayene yapılmalıdır. Çünkü, birçok deplase kırıkta dorsal deplasman mevcuttur. Hekim, volar yaralanma varlığını ve median sinir yaralanması olup olmadığını değerlendirmelidir. Eğer açık yara mevcut ise, steril pansuman ve atel uygulanarak radyolojiye gönderilmelidir. Bu şekilde, yumuşak doku hasarının artması engellenmiş ve hasta da rahatlamış olacaktır.

\section{Cerrahi Dışı Tedavi}

Deplase kırıklara en iyi yaklaşım acil serviste sedasyon altında yapılacak kapalı redüksiyon ve alçı uygulamasıdır (Şekil 2). Traksiyonun ardından, deformite tarafına doğru kibarca tamamlayıcı kuvvet uygulanır. Bu şekilde, kompresyon tarafındaki periost rahatlatılır. Ardından, distal parça proksimal parça üzerinden kaydırılarak redüksiyon sağlanır. İyi biçimlendirilmiş, şeker maşası şeklindeki atel veya alçı uygulaması redüksiyonun devamına yardımcı olacaktır. Kırıklar genellikle dorsale deplasedir. Kırıkların yalnız \%1'i volar deplasman gösterir. Volar deplasman genellikle el bileği ekstansiyonda immobilizasyon gerektirir.
Önkolun supinasyon pozisyona alınması, üç nokta tekniğiyle volarden molde edilecek şekilde yapılacak alçı uygulamasını kolaylaştırır. Dorsale deplase kırıklarda önkol nötral pozisyonda yapılacak immobilizasyon yeterlidir. ${ }^{10]}$ Alçı uygulaması sırasında el bileğinin ulnar deviyasyonu brakiyoradyalis kasının neden olacağı deplasmana engel olur. ${ }^{[1]}$ Eğer alçı uygulaması yapıldıysa, şişlik açısından mutlaka izlenmelidir. Redüksiyon ve atel-alçı uygulamasını takiben radyografik görüntüleme ve tekrarlı yapılacak fizik muayene çok önemlidir. Hastaların büyük kısmı elevasyon ve dolaşım takibinin ardından aynı gün taburcu edilir. Ancak, ciddi ağrısı olan, şiddetli şişliği bulunan fizik muayenesinden emin olunamayan hastalar hastanede izlenmelidir. İzlem için yatırılan hastalarda el bileğinin elevasyonu, sık yapılacak nörovasküler muayene ve ağrı kontrolü takip parametreleridir. Ağrı tedavisi, olası kompartman sendromu veya akut karpal tünel sendromu (AKTS) bulgularını maskeleyecek düzeyde olmamalıdır. Bu komplikasyon daha çok adolesan çağı çocuklarda distal radius dorsal angülasyonu bulunan ve deplase metafiz veya fizis kırıklarında izlenir. Semptomlar yaralanma sonrası bir iki saat içinde hızla ilerler. Hastalar, elevasyon ve bandaj uygulamasına cevap vermezler. Median sinir semptomlarının elevasyonla azalmaması, tersine progresif bir seyir göstermesi durumunda, acil olarak karpal tünelin cerrahi gevşetmesi yapılmalıdır.

\section{Metafiziyel kırıklarda kabul edilebilir redüksiyon parametreleri}

Geriye kalan büyüme zamanı, hasta yaşı, kırığın lokalizasyonu, deformitenin hangi düzlemde olduğu, kabul edilebilir redüksiyon parametreleri üzerine etkilidir. Anlamlı büyüme $(8 \mathrm{~mm} / \mathrm{yıl})$, fizise olan yakınlık, kırığın genellikle hareket düzleminde oluşu gibi nedenlerden ötürü, distal radius kırıklarında remodelizasyon (remodelling) potansiyeli yüksektir. Illk olarak, daha az stabil ve büyük miktarda açılanmasına rağmen translasyon veya Bayonet apozisyonu hemen daima yeniden şekillenir. Ikinci olarak, sagittal düzlem deformiteleri genellikle remodelize olur. Üçüncü olarak, 11 yaşından küçük çocuklarda distal radius kırıkları genellikle remodelize olur. Daha büyük çocuklarda remodelizasyon anlamlı deformiteyle birlikte görülür. Genellikle 10 yaşından küçük bir çocukta sagittal düzlemde $30-35^{\circ}$ ve koronal planda $20^{\circ}$ 'lik bir açılanma kabul edilebilir. Kabul edilebilir angülasyon miktarı yaşla beraber azalır. Kalan büyüme miktarı bir yıl olan bir çocukta, sagittal düzlem angülasyonu $15-20^{\circ}$ olarak kabul edilir. ${ }^{[10]}$

Komplet deplasmanlı distal radius kırı̆̆ı olan, 10 yaşından küçük 51 hastayı içeren bir çalışmada hastalar, sedasyon veya lokal anestezi yapılmadan kibarca 


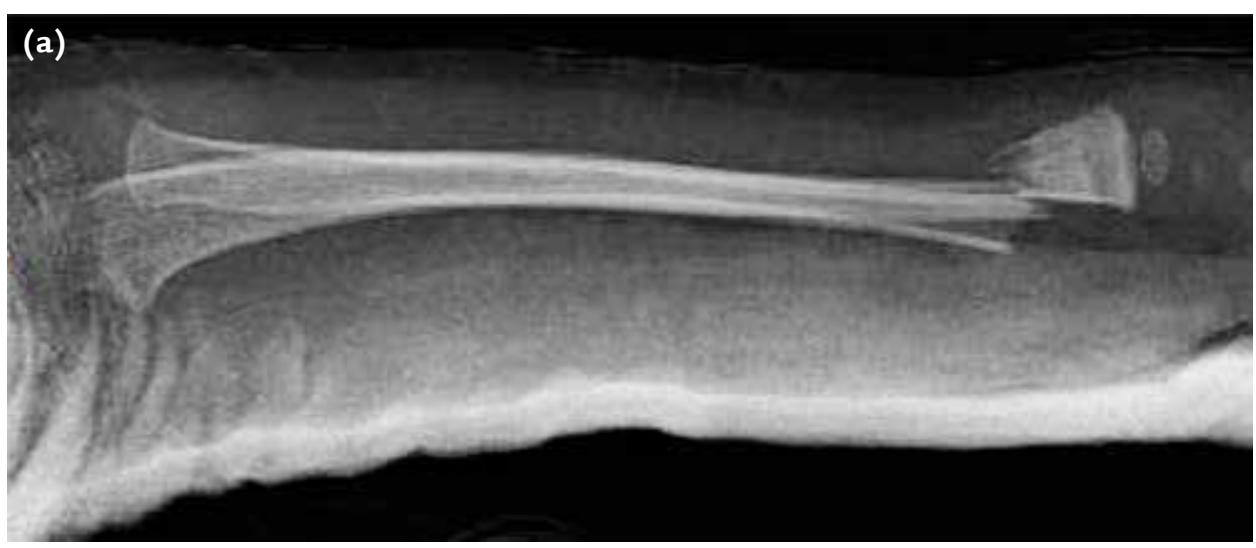

Şekil 2. a-d. Distal radius ve ulna dorsale deplase kırığı olan, beş yaşında erkek hastaya, kapalı redüksiyon ve uzun kol alçı uygulaması. (Harran Üniversitesi Araştırma ve Uygulama Hastanesi arşivinden)
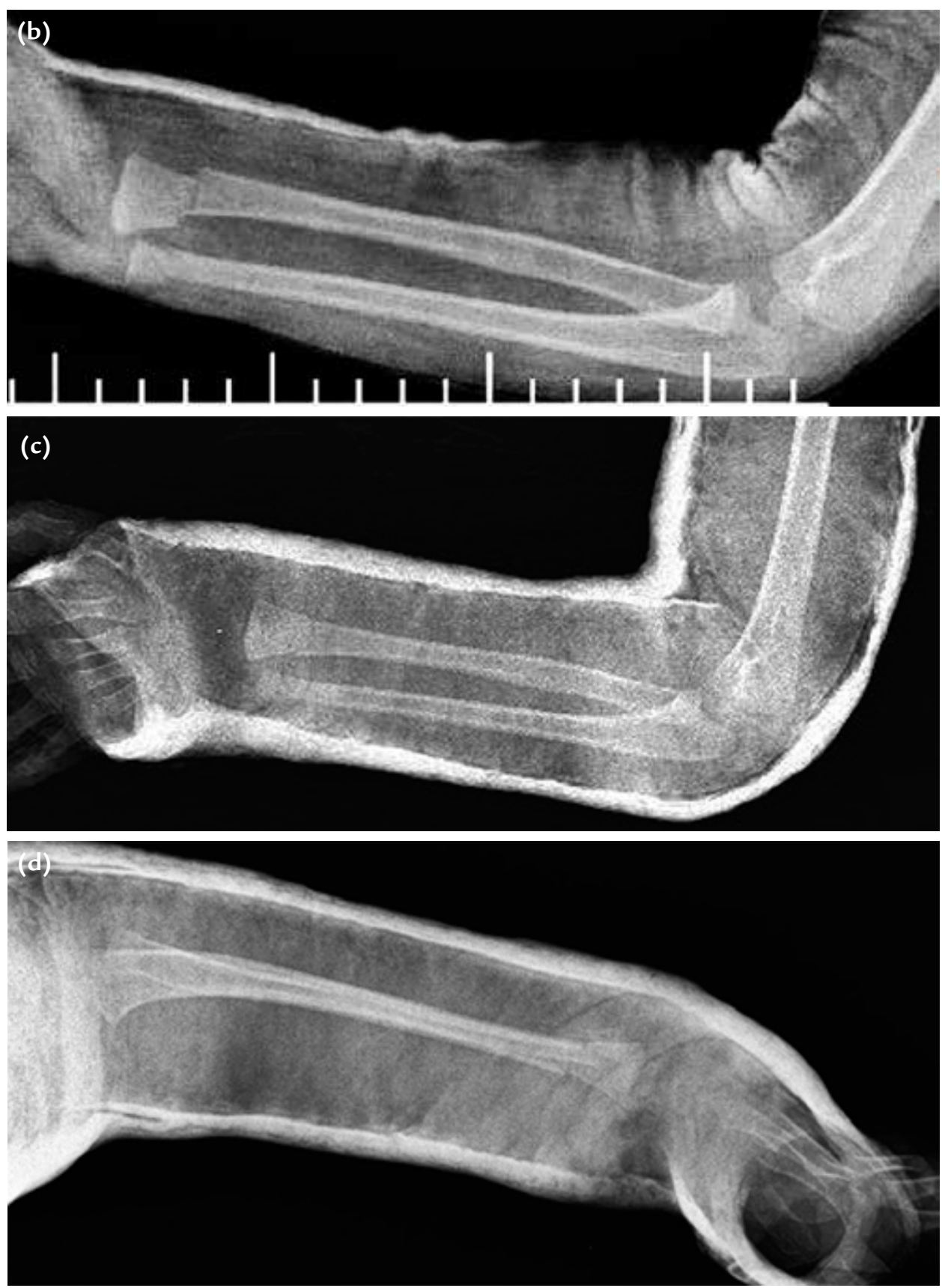
yapılan bir manipülasyonla normalden $10^{\circ}$ 'lik açılanma kabul edilerek izlenmiştir. Sagittal planda translasyon ve kırık parçalarının üstüste binmesi (Bayonet apozisyonu) kabul edilmiş; takiplerinde tüm hastalarda tam eklem hareketi ve radyolojik olarak kaynama olduğu bildirilmiştir. ${ }^{[12]}$

Redüksiyon kaybının incelendiği diğer bir çalışmada, tekrar açılanma hem ön-arka hem de yan grafide $15^{\circ}$ ve üstü olarak kabul edilmiş; 12 yaşından küçük çocuklarda tekrar redüksiyon denenmesinin sonuçları değiştirmediği, 12 yaşından büyük çocuklarda da konservatif takip ile çok iyi sonuçlar elde edildiği bildirilmiştir. Yazar, dokuz yaş altında $30^{\circ}$, dokuz ile 12 yaşlar arası $25^{\circ}, 12$ yaşından büyük çocuklarda ise $20^{\circ}$ 'ye kadar açılanmanın kabul edildiğini bildirmiş ve tekrarlı manipülasyon önermemiştir. ${ }^{[13]}$

\section{Uygun alçı tekniği}

Alçıyı değerlendirmek için birçok metod geliştirilmiştir. Tüm yöntemlerdeki hedef, efektif bir şekilde redüksiyon devamını sağlamaktır. Alçı indeksi, lateral grafideki alçının iç kenarları arasındaki mesafenin, önarka grafıdeki aynı mesafeye bölümüdür. Redüksiyon kaybını öngörmek ve alçı başarısını değerlendirmek açısından oldukça iyi bir yöntemdir. ${ }^{14]}$

Önkol ve el bileği kırığına alçı uygulanan 558 çocuk hastada yapılan çalışmada, hastalarda başlangıçtaki kırık redüksiyonunun bozulduğu ve bozulmayan gruba göre alçı indeksinde anlamlı farklılık tespit edilmiştir. ${ }^{[15]}$

Başka bir çalışmada, 113 hasta kısa veya uzun kol alçıyla tedavi edilmiş. Alçı indeksi $>0,79$ hastalarda, alçı indeksi 0,71 olan hastalara göre anlamlı redüksiyon kaybı görülmüştür. ${ }^{[16]}$

\section{Kısa kol ve uzun kol tartışması}

Redüksiyonun devamı için deplase kırıklarda alçının uygun uzunluğu konusunda tartışmalar mevcuttur. Geleneksel olarak deplase distal radius kırıklarında redüksiyon sonrası uzun kol alçı uygulanır. Yaygın düşünce dirsek hareketleriyle özellikle pronasyon/supinasyonun kısıtlanmasıyla redüksiyon kaybının önleneceğidir. Redüksiyonun devamında kısa kol alçı uygulamasının eşdeğer etkinlikte olduğu gösterilmiştir. ${ }^{[8,9]}$ Bununla birlikte, kısa kol alçı uygulaması, önkol kırığı olan çocuklarda supinasyon ve pronasyon nedeniyle oluşan ağrıyı önlemede yetersiz kalmaktadır. Bu yüzden, önkol kırığında uzun kol alçı uygulaması, daha az ağıı ve daha rahat immobilizasyon sağlaması nedeniyle tercih edilmektedir. Ayrıca, redüksiyon ve alçı immobilizasyonu sonrası ağrının en fazla olduğu ilk 48-72 saat, uzun kol alçı uygulanan hastalarda analjezik ihtiyacının daha az olduğu gösterilmiştir. ${ }^{[17]}$ Kısa kol alçıyı savunanlar, çocukların okuldan daha az geri kaldığını ve günlük aktivitelerini daha rahat yaptıklarını savunmaktadırlar. ${ }^{[8]}$

Redüksiyon kalitesi ve alçının uygun şekilde biçimlendirilmesi, alçı uzunluğundan daha önemli bir faktördür. ${ }^{[18]}$

\section{Hasta takibi}

Alçı uzunluğundan veya redüksiyon kalitesinden bağımsız olarak, deplase distal radius kırıklarının yaklaşık 1/3'ünde redüksiyon kaybı izlenir. Bu da, yakın radyolojik takibin ne kadar önemli olduğunu gösterir. ${ }^{[19]}$ Birçok faktör, geç görülen deplasmana neden olabilir: başlangıçtaki deplasman miktarı (translasyon $50^{\circ}$ 'den fazla; angülasyon $30^{\circ}$ 'den fazla; Bayonet apozisyonu), tam olmayan redüksiyon, beraberinde görülen distal ulna kırığı, kötü alçılama tekniği vb. Haftalık klinik ve radyolojik takip, 2-3 hafta boyunca önerilir. Yaralanmadan sonraki ilk 2-3 haftada oluşacak redüksiyon kaybı, tekrar kapalı redüksiyon ile düzeltilebilir (Şekil 3). Birçok kırıkta alçı 4-6 hafta tutulur. Çocuğun yaşına bağlı olarak 2-3 ay içerisinde tüm aktivitelerine dönmesi beklenir.

\section{FiZIYEL KIRIKLAR}

Distal radiusun fizis kırıkları, çocuklarda en sık görülen büyüme plağı yaralanmalarıdır. Bu yaralanmaların çoğu (\%80) SH Tip 1-2 kırıklarıdır. Büyümenin durması riski, distal radius fizis kırıklarında yaklaşık \%4'tür. Nadir olmasına rağmen büyümede bozulmaya neden olabileceğinden, bu kırık türü metafiziyel kırıklardan ayrı incelenir. Kısa dönemdeki yaklaşım metafiziyel kırıklardakine benzer şekildeyken, bazı önemli farklar bulunmaktadır. ${ }^{[18]}$ Bu tür kırıklarda, remodelling 10 yaşına kadar çocuklarda daha iyidir. ${ }^{[20]}$ Cerrahi tedavi için mutlak tek endikasyon SH Tip 3-4 kırıklardır. Bu tür kırıklar eklem içi kırıklar olup, anatomik redüksiyon ve Kirschner teli (K-teli) tespiti ile tedavi edilmelidir.

\section{Nondeplase Kırıklar}

Nondeplase veya minimal deplase kırıklar, distal radyal fiziste yaygın görülür. Hastalar, açık el üzerine düşme sonucu, el bileğinde deformite veya anlamlı şişlik görülmeden, el bileği ağrısıyla başvururlar. Fizik muayenede, distal radyal fiziste nokta hassasiyeti izlenir. Radyografide nondeplase veya minimal deplase kırık görülebilir (SH Tip 1-2). Bu tür kırıklar, metafızde izlenen torus kırıklarına benzer şekilde, 3-4 hafta immobilizasyonla tedavi edilir. Bununla beraber, radyografide normal görülmesi durumunda sıklıkla gizli SH Tip 1 kırığı tanısı alır. Bu yaralanma çoğu zaman el bileği burkulması veya kontüzyonu ile karışabilir. Aktivite sırasında duyulan ağrı ve tekrar yaralanma riski nedeniyle, bu tip kırıklar alçı immobilizasyonuyla tedavi edilmelidir. 


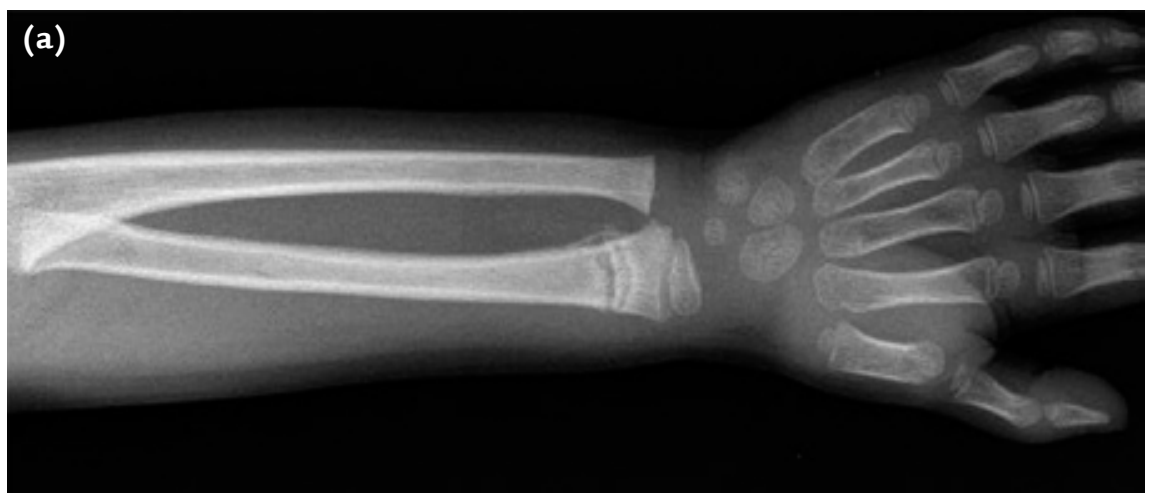

Şekil 3. a-d. Dört yaşında erkek hastanın distal radius kırı̆̆ı. İki hafta sonraki kontrol filminde görülen redüksiyon kaybı ardından, tekrar redüksiyon ve perkütan pinleme. (Harran Üniversitesi Araştırma ve Uygulama Hastanesi arşivinden)
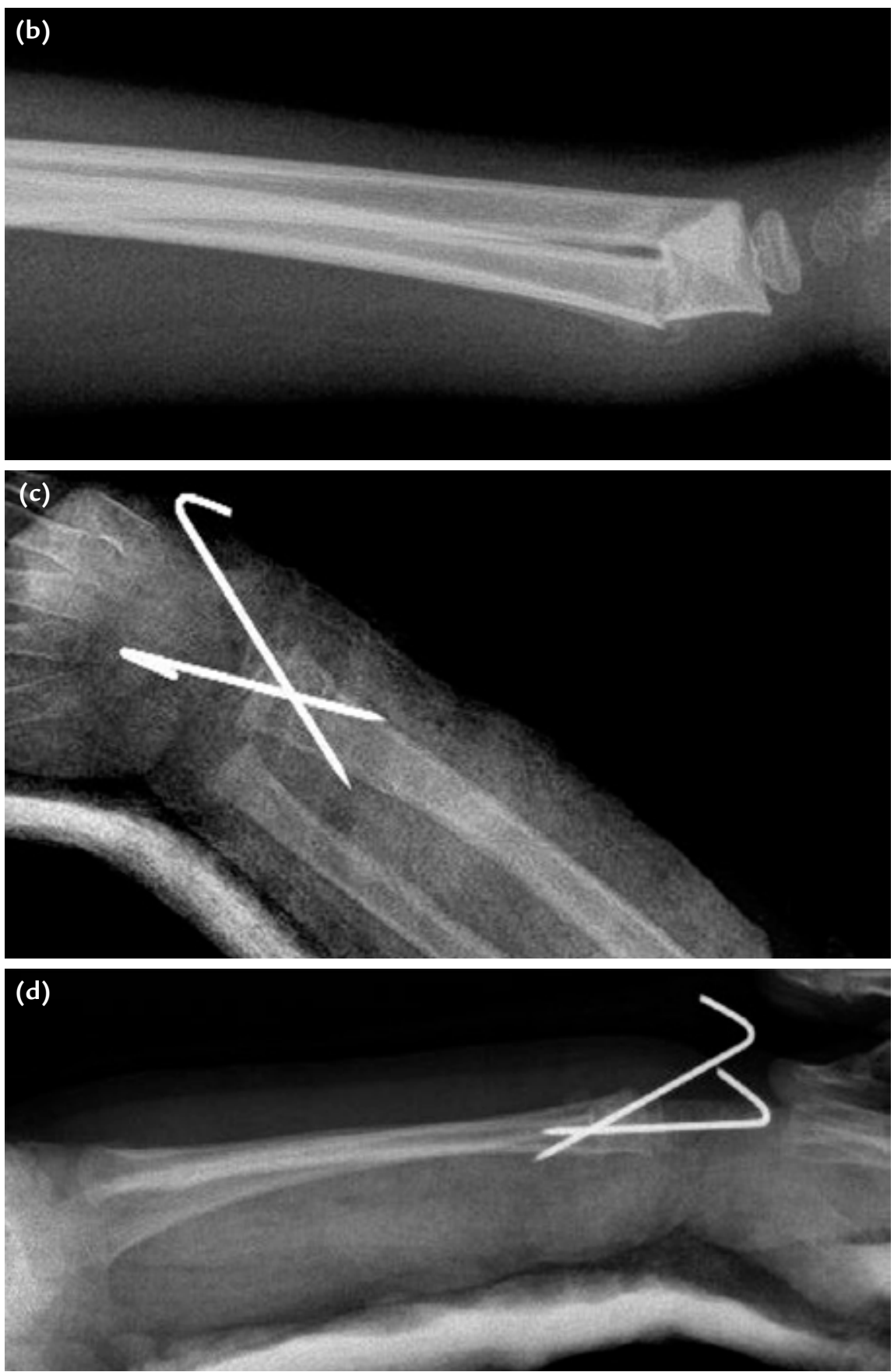


\section{Deplase Kırıklar}

\section{SH Tip 1-2 kırıklar}

Deplase distal radius fizis kırıklarının büyük çoğunluğunu oluşturur. Acil serviste sedasyon altında yapılacak kapalı redüksiyon en iyi tedavi yaklaşımı olmakla beraber, redüksiyon için agresif manevra veya aşırı güç uygulamaktan kaçınılmalıdır. Traksiyon ve kibarca yapılacak redüksiyon ile, fizisin makaslama güçlerinden korunması gereklidir. Ayrıca, art arda uygulanacak redüksiyonlardan kaçınılmalıdır. Fizis iyileşmesi metafiziyel kırıklardaki iyileşmeden daha hızlı olduğundan, deplase SH Tip 1-2 kırıklara 7-10 gün sonra kapalı redüksiyon yapılması önerilmez. Geç yapılacak redüksiyon manevrası iyatrojenik fizis yaralanması nedeniyle büyümenin durmasına neden olabilir. Remodelling kapasitesinin çok yüksek olması nedeniyle, bu tür yaralanmalarda deformitenin izlenmesi önerilir. Hızlı iyileşme nedeniyle redüksiyon kaybının tespiti için 5-7 günlük kontroller ile takip sağlanır. Alçı uygulaması dört hafta kadar tutulur. Bundan sonra tipik olarak tamamen iyileşme görülür. Alçının sonlandırılmasından sonra atel uygulaması ve el bileği egzersizleri önerilebilir. Günlük aktivitelere tam anlamıyla dönüş, 8-12 hafta sonrası beklenir. Büyümenin durmasıyla ilgili endişeler nedeniyle, hastanın iskelet matüritesi oluşana kadar altı aylık aralarla radyolojik olarak izlenmesi uygundur. ${ }^{[18]}$

\section{SH Tip 3-4 Kırıklar}

Oldukça nadir (\%4-5) ve nispeten büyük çocuklarda ve aksiyel yüklenmenin görüldügüü yüksek enerjili yaralanmalarda izlenir. Düz radyografiler, kırık paterni ve deplasmanını değerlendirmede yetersiz kalabilir. Bu durumlarda, bilgisayarlı tomografi (BT) ile değerlendirmek gerekebilir. Nondeplase kırıklar, nondeplase SH Tip 1-2 kırıklar gibi tedavi edilebilir. Deplase kırıklar özel dikkat ister. Çünkü bu kırıklar fizisi içine alan eklem içi kırıklardır. Uygun şekilde iyileşmesi için anatomik dizilim sağlanması gerekir. Bazı olgularda kapalı redüksiyon ve alçılama yeterli görülürken, birçok olguda redüksiyon ve perkütan pinleme veya açık redüksiyon ve internal tespit gereklidir. ${ }^{[18]}$

\section{DISTAL ULNA KIRIKLARI}

\section{Metafiziyel Kırıklar}

Distal ulnar metafiziyel kırıklar, büyük çoğunlukla açık el üzerine düşme sonucu, aynı tarafta distal radius kırığı ile beraber izlenir. Çoğu distal ulna kırı̆̆ı distal radius kırığının redüksiyonuyla redükte olur. Eğer radiusun redüksiyonu kabul edilebilir sınırlarda ise Bayonet apozisyonu ve $20-30^{\circ}$ 'lik angülasyon ulna için kabul edilebilir sınırlardır. Nadir olgularda, perkütan redüksiyon ve pinleme veya açık redüksiyon kabul edilemeyen dizilim durumlarında endikedir.

\section{Fizis Kırıkları ve Stiloid Kırığı}

SH kırıkları yaygın olarak görülmez. Ulnar SH Tip 1-2 kırıkları en çok distal radius kırıklarıyla beraber görülür. Ulnar stiloid (veya epifiz) kırığı, distal radius kırıklarının üçte birinde görülür. ${ }^{[10]}$ Metafiziyel ulna kırıklarında olduğu gibi, radius kırığının redüksiyonu sırasında pasif bir şekilde redükte olur; sorunsuz bir şekilde kaynar. Klinik ve radyolojik olarak bu kırıkların izlenmesi önemlidir, çünkü büyümenin durması sonucu ulnar kısalma görülebilir. Distal ulnar fizis yaralanması sonucu büyümenin durması, \%55 gibi yüksek oranda görülür. Bu oran, distal radiusta izlenenden çok daha yüksektir. ${ }^{[21]}$ Çocuk ve adolesanlarda, birçok olguda, ulnar stiloid kırığı distal radius kırı̆̆ı ile beraber izlenir. Radiusun alçı ile tedavisi sırasında ulnar stiloid kırıklarının bir kısmı iyileşirken, çoğunluğu radyolojik olarak kaynamaz. Bu kaynamamaya rağmen hastaların çok büyük bir bölümünde klinik sonuçlar çok iyidir. Ulnar tarafta el bileği ağrısı, instabilite veya fonksiyonel kısıtlılık izlenmez. ${ }^{[22]}$ Çünkü hastaların büyük çoğunluğunda TFK sağlamdır ve distal radyoulnar eklem (DRUE) stabilitesi korunmuştur. Ulnar stiloidin semptomatik kaynamaması, el bileğinde ulnar tarafta ağrı ve hareket sırasında "klik" ile klinikte kendini gösterir. Ulnar stiloid kırığı bulunan nadir olgularda ise yüksek enerjili travma sonucu DRUE instabilitesi izlenir. Bu tür bir kırık tespit edileceğinde bazı yazarlar gergi bandı tespiti ve TFK onarımını önermektedirler. ${ }^{[18]}$

\section{PEDIATRIKK GALEAZZi KIRIĞI}

DRUE ayrışması ile beraber distal radius kırıkları, Galeazzi kırıkları olarak adlandırılır. Bu kırıklar, ileri derecede pronasyondaki el bileğine aksiyel yüklenme ile oluşur. Pediatrik hastalarda DRUE instabilitesi büyük çoğunlukla deplase distal ulnar fiziyel yaralanmanın sonucu olarak görülür. Tedavinin amacı, distal radius migrasyonunu engellemek ve distal radyoulnar eklemi tespit etmektir. Yetişkinlerin aksine çocuklarda, DRUE'yi stabilize eden bağlar sağlam kalarak, kırılan ulnar epifiziyel parçaya yapışık olur. Bu nedenle, çocuklarda görülen Galeazzi kırıklarının büyük çoğunluğunda kapalı redüksiyon ve önkolun supinasyonda alçı uygulamasıyla çok iyi klinik sonuç elde edilir. Daha büyük çocuklarda, Galeazzi kırıkları için açık redüksiyon gerekebilir. Bu durumda, rijid plak tespitini tercih etmek gerekir. ${ }^{[10]}$ Eğer redüksiyon ve stabilizasyon sonrası distal radyoulnar eklem instabil ise, eklem supinasyonda redükte edilir ve ulnadan radiusa transvers K-teli uygulanabilir. Ekstansör karpi ulnaris veya periostal yapının araya girmesi nedeniyle redükte edilemeyen DRUE ayrışması durumunda cerrahi tedavi uygulanabilir. Bu yaralanmanın uzun dönem sekeli olarak supinasyon ve pronasyon kısıtlılığı, ulnar sinir disfonksiyonu ve ısrar eden DRUE instabilitesi görülebilir. 


\section{CERRAHI TEDAVi}

Cerrahi endikasyonlar: Açık kırıklar, redükte olmayan kırıklar, kompartman sendromu veya karpal tünel sendromu olan kırıklar, şiddetli şişlik bulunan kırıklar (alçı önerilmez), aynı tarafta stabilizasyon gerektiren kırığı olan (suprakondiler humerus kırığı gibi, alçı önerilmez), redüksiyon kaybı nedeniyle tekrar manipülasyon ihtiyacı olan kırıklar. ${ }^{[23]}$ Masif yumuşak doku yaralanmalarında, eksternal fiksatör uygulaması bir rezerv tedavi seçeneği olarak görülmelidir. Kırıklar araya giren yumuşak doku nedeniyle redükte edilemeyebilir. Dorsale deplase kırıklarda yumuşak doku, genellikle pronator kuadratus veya fleksör tendonlardır. ${ }^{[24]}$ Nadir olarak görülen volare deplase kırıklarda ise ekstansör tendonlar araya girebilir. Tekrar redüksiyon ihtiyacı olan hastalar, genellikle daha büyük çocuklardır. Bu tür hastalarda K-teli ile tespitten kaçınmamak gerekir. ${ }^{[25]}$ Kompartman sendromu veya karpal tünel sendromu şüphesi olduğu durumlarda hemen kırığın stabilizasyonu gerekir. Çünkü stabilizasyon yumuşak doku hasarının artmasını engeller.

\section{Açık Kırıklar}

Açık kırıkların ilk tedavisinde enfeksiyondan korunmada en önemli faktör, intravenöz (i.v.) antibiyotik uygulamasıdır. Daha sonra, kırık sedasyon altında kapalı redükte edilir. Yaraya steril pansuman yapılır ve ardından atel veya alçı uygulanır. Açık kırıklarda, ameliyathanede irrigasyon ve debridmanın en erken dönemde yapılması uygundur. Pediatrik hastalarda izlenen enfeksiyon oranları yetişkinlerdekine benzerdir. Yaralanmadan sonra 6-8 saat içinde cerrahi uygulanan hastada, 8-24 saat sonra cerrahi uygulananlara göre daha düşük enfeksiyon oranları saptanmıştır. ${ }^{[26]}$ Ameliyathanede açık yara, kırık sonlanmalarını görecek şekilde genişletilir; ölü dokular temizlenir, irrigasyon yapılır; yumuşak dokunun durumuna göre primer kapatılabilir veya negatif basınçlı yara tedavisi uygulanabilir. Tekrarlı cerrahi debridman gerekebilir. Birçok olguda cerrahi tespit ve atel uygulaması yapılır. Son yapılan irrigasyon ve debridmanı takip eden 24-48 saat içerisinde i.v. antibiyotik tedavisine devam edilir.

\section{Kapalı Redüksiyon ve Pinleme}

İnstabil distal radius kırıklarında dizilimin sağlanması için kapalı redüksiyon ve perkütan pinleme uygun bir tedavidir. Bazı metafiziyel ve metadiyafiziyel kırıklarda pin ile tespit proksimalden fizise doğru sağlanabilirken, çoğu metafiziyel kırıklarda tespit fizisten proksimale doğru yapılır. Pinleme sonrası kısa veya uzun kol alçı uygulanır. Genellikle cerrahi sonrası 3.-4. haftada, cerrah radyolojik iyileşmeyi teyit ederek pinleri çekebilir.
Son yapılan çalışmalarda, redüksiyon sonrası ilk iki hafta içerisinde redüksiyon kaybının \%21-34 olduğu gösterilmiştir. ${ }^{[19,27]}$ Redüksiyon kaybını önlemek için deplase distal radius kırıklarının redüksiyonu ve perkütan K-teli tespiti sonrası alçı immobilizasyonu uygulanabilir. ${ }^{[1,19]}$

K-teli tespitini savunanlar; redüksiyon kaybını gösteren önemli prediktif faktörlerin ilk gelişteki komplet deplasman miktarı, ulnada ilave kırık, sedasyon ve/ veya lokal anestezi altında yapılan manipülasyon olduğunu, tamamen deplase radius distal kırığı olan hastalarda mükemmel redüksiyon elde edilse dahi, genel anestezi altında K-teli tespiti yapılması gerektiğini ileri sürmektedirler. ${ }^{[19]}$ Başka çalışmalarda da, kapalı redüksiyon ve alçılama ile perkütan pinleme karşılaştırılmış, benzer klinik sonuçlar raporlanmıştır. ${ }^{[28]}$

Birçok çalışma, kapalı redüksiyon ve pinlemenin ardından görülebilen pin dibi enfeksiyonunun nadir olduğunu ve görüldüğünde de enfeksiyonun yüzeyel olduğunu bildirmiştir. ${ }^{[28,29]}$ Yüzeyel enfeksiyonlar, genellikle pin dibi bakımı ve oral antibiyotiğe iyi cevap verir; nadiren cerrahi gerekir.

Uzun dönem geriye yönelik yapılan 884 olgunun tarandığı bir çalışmada, sadece $12(\% 1,4)$ olguda pin ile ilişkili ciddi enfeksiyon saptanmıştır. Tanılar içerisinde; selülit, osteomiyelit, septik artrit ve yumuşak doku absesi bulunmaktadır. ${ }^{[30]}$ Pin dibi enfeksiyonunun erken tanınması, derin yumuşak doku absesine veya osteomiyelite ilerleme riskini önlemek açısından önemlidir.

\section{Açık Redüksiyon ve İnternal Tespit}

En sık endikasyonlar; açık, kapalı redükte olmayan, yanlış kaynama nedeniyle osteoklazis gerektiren ve eklem içi kırıklardır. Plak ile tespit bir seçenek olmakla beraber açık kırık tespitinde K-teli kullanımı daha yaygındır. Açık redüksiyon ve plak uygulamasının endike olduğu durumlar; parçalı kırıklar ve SH Tip 3-4 eklem içi kırıklardır.

\section{Dorsal yaklaşım}

Kapalı redükte edilemeyen veya tamamen iyileşmemiş metafizıyel kırıklarda en iyi yaklaşım, sınırlı dorsal yaklaşım ve perkütan pin tespitidir. Dorsal $2-3 \mathrm{~cm}$ 'lik el bileği insizyonu, brakiyoradyalis tendonunun ulnar kenarından yapılır. Ekstansör retinakulum açılır ve brakiyoradyalis ile ekstansör tendonlar ayrılarak kırık sahasına ulaşıır. Küçük bir elevatör yardımıyla, kırık hattına giren dokular kibarca çıkartılır; kallus dokusu temizlenir. Ardından, floroskopi eşliğinde açık redüksiyon yapılır ve kırık K-teli yardımıyla tespit edilir. SH Tip 3-4 kırıklarda, başvuru zamanından bağımsız olarak, eklem içi dizilimin tam olarak sağlanabilmesi için açık redüksiyon ve plak tespiti yapılır. 


\section{Volar yaklaşım}

Apeks-volar açılanması olan kırıklarda, en yaygın olarak bu yolla açık redüksiyon yapılır. Özellikle bu kırıkların eklem içi uzanımı varsa (örneğin, parçalı kırıklarda), plak tespiti gerektiğinde dorsal yüzden çok volar distal radius tercih edilir. Plak tespiti her yaş grubundaki metafiziyel kırıklarda uygulanabilirse de, iki yıldan daha az büyüme zamanı kalan adolesanlarda daha uygundur. ${ }^{[18]}$

\section{Komplikasyonlar}

En sık görülen komplikasyonlar; malunion, tekrar kırılma, büyümenin durması, periferik sinir yaralanması ve kompartman sendromudur. Bunun dışında; kaynamama, çapraz kaynama, aşırı büyüme, enfeksiyon, tendon yırtığı veya araya girmesi ve refleks sempatik distrofi komplikasyonları da bildirilmiştir.

\section{Malunion}

Radyolojik olarak en sık görülen komplikasyon olmakla beraber, semptomatik olanı çok nadirdir. En sık görülen problem, hastanın kozmetik görünümden memnuniyetsizliğidir. Bu durum, nadir görülen volare deplase kırıklarda izlenir; çünkü apeks-dorsal deformiteyi saran yumuşak doku daha azdır. Semptomatik malunion, iskelet gelişimini tamamlamamış hastalarda nadir olmakla birlikte, geliştiği durumda osteotomi ile düzeltilebilir. Geleneksel olarak drill yardımıyla osteoklazis ve alçılama şeklinde uygulanır. Açık osteotomi ve rijid internal tespit uygulamasını savunan yayınlar da vardır. ${ }^{[31]}$

\section{Büyümenin durması}

Distal radius fizis kırıklarında nadirdir (\%4). ${ }^{[18]}$ Risk konusunda hasta ve ailesi bilgilendirilmelidir. Bu durum nadir olmakla birlikte ve genellikle de SH Tip 5 crush yaralanma (fizisin yaralanması) olmasıyla beraber, tanı ancak geriye dönük olarak konulabilir. Distal radius fizis yaralanmasının erken tespiti, ancak distal radiustaki dizilimin bozulması veya ulnaya göre radiusta kısalmanın olduğunu (pozitif ulnar varyans) gösteren radyolojik bulgularla olur. Büyüme ile deformitedeki kötüleşme, hastalar tarafından, ulnar tarafta çıkıntı ve daha sık olarak aktiviteye bağlı el bileği ulnar taraf ağrısı ve hareket kısıtlılığı olarak bildirilir. Cerrahi girişimin endike olduğu durumlarda; ulnar varyansın düzeltilmesi, DRUE'nin restorasyonu ve ağrısız TFK elde edilmesi amaçlanır. Minimal deformitesi bulunan hastalar ve en az iki yıl büyüme zamanı kalan hastalarda, bar rezeksiyonu ve lokal yağ interpozisyonu uygulaması denenebilir. Barın uygulama noktasının kesinlikle tanımlanması kritik öneme sahiptir ve en güvenilir olarak manyetik rezonans (MR) görüntüleme ile tespit edilir. Deformite oluşmadan önce komplet radyal epifizyodez, ulnar kısaltma ve distal ulnar epifizyodez en iyi tedavi seçeneğidir. Eğer TFK patolojisinden şüpheleniliyorsa beraberinde el bileği artroskopisi gerekli olabilir. Distal radiusta büyümenin durması sonucu oluşan kompleks deformitelerde ise, radyal osteotomi ve ulnar taraf uzatma kombinasyonları endike olabilir. ${ }^{[18]}$

\section{Tekrar kırılma}

Distal önkolda proksimale göre daha az izlenir. Yeşil ağaç kırıklarından sonra, açık kırıklarda ve K-teli migrasyonu sonrası daha sık izlenir. ${ }^{[32]}$ Tekrar kırıkların konservatif olarak takibini savunanlar olduğu gibi, açık redüksiyon internal tespit ile (redüksiyon kaybı problemi) tedaviyi savunanlar da bulunmaktadır. ${ }^{[10,32]}$

\section{Periferik sinir yaralanması}

Genellikle geçicidir ve yaralanma sırasında kırığa bağlı gerilmeyle veya araya girmeyle ilişkilidir. Median sinir genellikle etkilenir. Semptomlar sıklıkla redüksiyon sonrası düzelir. Takılma veya sıkışma, yaralanma anında veya redüksiyon sırasında oluşabilir. Bu yüzden, nörolojik muayenenin tedavi öncesi yapılması önemlidir. ${ }^{[33]}$ Bu muayene, ağlayan çocukta zor olabilir; bu yüzden, muayenenin ebeveynin kucağında ve sağlam taraftan başlayarak, çocuğa güven vermek suretiyle yapılması uygun olur. Sinir fonksiyon kaybı eğer kapalı redüksiyon sonrası meydana gelmişse ve özellikle de anatomik redüksiyon sağlanamamışsa, cerrahi tedavi endikasyonu ortaya çıkar. Sinir fonksiyonlarında 6-12 hafta süresince düzelme izlenmezse elektrodiyagnostik çalışma ve cerrahi göz önünde bulundurulur.

\section{Kompartman ve akut karpal tünel sendromu}

Klinik bulgularla uyumsuz şiddetli ağrı, en önemli kilit bulgudur. Bu durumların başarılı yönetimi, tanı zamanlamasıdır. Her iki durum için de uyanık ve şüpheci olmak gerekir.

\section{Kaynamama, çapraz kaynama, enfeksiyon ve tendon yırtı̆̆ı}

Çocuk distal önkol kırıklarında bu komplikasyonlar nadirdir. Komplike olmayan kapalı kırıklarda genellikle kaynamama izlenmez. Kaynamama durumu, altında yatan başka bir patoloji düşündürür (konjenital psödoartroz veya osteomiyelit gibi). Çapraz kaynama durumunda uygulanan cerrahi rezeksiyonun, çocuklarda erişkinlere göre başarı oranı düşüktürr. ${ }^{34]}$ Tendon yaralanması, başlangıçta sinir yaralanması veya kompartman sendromu ile karıştırılabilir. Doğru tanı, dikkatli bir fizik muayene ile konulur. Tendon sıkışmasında, duyusal değişiklikler ve ağrı eşlik etmez ve bunlar genellikle redüksiyona dirençli kırık deplasmanıyla ilişkilidir. 


\section{Refleks sempatik distrofi (RSD)}

Ağrı ve vazomotor disfonksiyonla karakterize bir klinik durumdur. Daha çok travma sonrası yetişkinlerde ve üst ekstremitede izlenir. RSD, çocuklarda distal önkol kırıklarından sonra izlenebilse de alt ekstremitede daha yaygındır. Çocuklarda görülen RSD tedavisi; fizik tedavi, fizyolojik tedavi, transkütan elektrik stimülasyonu ve trisiklik antidepresan tedavilerine yanıt verir.

\section{ÖZET}

Distal radiusun metafiziyel ve fiziyel kırıkları çocuklarda yaygın olarak görülür. Birçok olguda en iyi tedavi, kapalı redüksiyon ve alçılamadır. Redüksiyon ve alçılama prensipleri uygun olarak tatbik edildiğinde, klinikteki farklı uygulamalara rağmen, bu yaralanmalarda uzun dönem sonuçlar genellikle çok iyidir. Cerrahi endikasyonlar; açık, eklem içi, redükte olmayan ve redüksiyon kaybına uğrayan instabil kırıklardır. Cerrahi olarak en yaygın uygulanan tedavi kapalı redüksiyon ve perkütan pin tespiti olmakla beraber, özellikle adolesan çağda izlenen eklem içi kırıklarda, açık redüksiyon ve plak tespiti de genel olarak uygulanan tedaviler arasındadır. Ortopedi doktorunun dikkat etmesi gereken en önemli komplikasyonlar; AKTS, büyümenin duraklaması ve bir de bu problemlerin uzun dönem takibidir.

\section{KAYNAKLAR}

1. Sengab A, Krijnen $P$, Schipper IB. Displaced distal radius fractures in children, cast alone vs additional K-wire fixation: a meta-analysis. Eur J Trauma Emerg Surg 2018. Crossref

2. Randsborg $\mathrm{PH}$, Gulbrandsen $\mathrm{P}$, Benth JS, Sivertsen $\mathrm{EA}$, Hammer OL, Fuglesang HFS, Årøen A. Fractures in children: epidemiology and activity specific fracture rates. J Bone Joint Surg Am 2013;95:e42(1-4). Crossref

3. Hedström EM, Svensson $O$, Bergström $U$, Michno $P$. Epidemiology of fractures in children and adolescents. Acta Orthop 2010;81(1):148-53. Crossref

4. Peterson HA. Physeal fractures: Part 3. Classification. J Pediatr Orthop 1994;14(4):439-48. Crossref

5. Vernooij CM, Vreeburg ME, Segers MJ, Hammacher ER. Treatment of torus fractures in the forearm in children using bandage therapy. JTrauma Acute Care Surg 2012;72(4):10937. Crossref

6. Kropman RHJ, Bemelman M, Segers MJM, Hammacher ER. Treatment of impacted greenstick forearm fractures in children using bandage or cast therapy: a prospective randomized trial. J Trauma 2010;68(2):425-8. Crossref

7. Aminian A, Schoenecker PL. Premature closure of the distal radial physis after fracture of the distal radial metaphysis. J Pediatr Orthop 1995;15(4):495-8. Crossref

8. Bohm ER, Bubbar V, Yong Hing K, Dzus A. Above and below-the elbow plaster casts for distal forearm fractures in children. A randomized controlled trial. J Bone Joint Surg Am 2006;88(1):1-8. Crossref
9. Webb GR, Galpin RD, Armstrong DG. Comparison of short and long arm plaster casts for displaced fractures in the distal third of the forearm in children. J Bone Joint Surg Am 2006;88(1):9-17. Crossref

10. Herring JA, Ho C. Chapter 33: Upper extremity injuries. In: Herring JA, editor. Tachdjian's Pediatric Orthopaedics, 5th ed. Philadelphia: Elsevier Saunders; 2014. pp.1245-352.

11. Edmonds EW, Capelo RM, Stearns P, Bastrom TP, Wallace $C D$, Newton PO. Predicting initial treatment failure of fiberglass casts in pediatric distal radius fractures: utility of the second metacarpal-radius angle. J Child Orthop 2009;3(5):375-81. Crossref

12. Crawford SN, Lee LS, Izuka BH. Closed treatment of overriding distal radial fractures without reduction in children. J Bone Joint Surg Am 2012;94(3):246-52. Crossref

13. Roth KC, Denk K, Colaris J W, Jaarsma RL. Think twice before re-manipulating distal metaphyseal forearm fractures in children. Arch Orthop Trauma Surg 2014;134(12):1699707. Crossref

14. Debnath UK, Guha AR, Das S. Distal forearm fractures in children: cast index as predictor of re-manipulation. Indian J Orthop 2011;45(4):341-6. Crossref

15. Chess DG, Hyndman JC, Leahey JL, DCS Brown, Sinclair AM. Short arm plaster cast for distal pediatric forearm fractures. J Pediatr Orthop 1994;14(2):211-3. Crossref

16. Webb GR, Galpin RD, Armstrong DG. Comparison of short and long arm plaster casts for displaced fractures in the distal third of the forearm in children. J Bone Joint Surg Am 2006;88-A(1):9-17. Crossref

17. Giacalone M, Capua T, Shavit I. Short and long arm cast and pain after discharge in children who underwent reduction of distal forearm fracture in the Emergency Department: A study protocol for a randomized comparative effectiveness study. Contemp Clin Trials Commun 2018;11:46-9. Crossref

18. Pannu GS, Herman M. Distal Radius-Ulna Fractures in Children. Orthop Clin North Am 2015;46(2):235-48. Crossref

19. Zamzam MM, Khoshhal KI. Displaced fracture of the distal radius in children: factors responsible for re-displacement after closed reduction. J Bone Joint Surg $\mathrm{Br}$ 2005;87$B(6): 841-3$. Crossref

20. Houshian S, Holst AK, Larsen MS, Torfing T. Remodeling of Salter-Harris type II epiphyseal plate injury of the distal radius. J Pediatr Orthop 2004;24(5):472-6. Crossref

21. Golz RJ, Grogan DP, Greene TL, Belsole RJ, Ogden JA. Distal ulnar physeal injury. J Pediatr Orthop 1991;11(3):318-26. Crossref

22. Abid A, Accadbled F, Kany J, de Gauzy JS, Darodes P, Cahuzac JP. Ulnar styloid fractures in children: a retrospective study of 46 cases. J Pediatr Orthop B 2008;17(1):15-9. Crossref

23. Noonan $\mathrm{KJ}$, Price $\mathrm{CT}$. Forearm and distal radius fractures in children. J Am Acad Orthop Surg 1998;6(3):146-56. Crossref

24. Holmes JR, Louis DS. Entrapment of pronator quadratus in pediatric distal-radius fractures: recognition and treatment. J Pediatr Orthop 1994;14(4):498-500. Crossref

25. Yung SH, Lam CY, Choi KY, Ng KW, Maffulli N, Cheng JCY. Percutaneous intramedullary Kirschner wiring for displaced diaphyseal forearm fractures in children. J Bone Joint Surg $\mathrm{Br}$ 1998;80-B(1):91-4. Crossref

26. Skaggs DL, Friend L, Alman B, Chambers HG, Schmitz M, Leake B, Kay RM, Flynn JM. The effect of surgical delay on acute infection following 554 open fractures in children. J Bone Joint Surg Am 2005;87(1):8-12. Crossref 
27. Asadollahi S, Ooi KS, Hau RC. Distal radial fractures in children: risk factors for redisplacement following closed reduction. J Pediatr Orthop 2015;35(3):224-8. Crossref

28. Miller BS, Taylor B, Widmann RF, Bae DS, Snyder BD, Waters PM. Cast immobilization versus percutaneous pin fixation of displaced distal radius fractures in children: a prospective, randomized study. J Pediatr Orthop 2005;25(4):490-4. Crossref

29. Hsu LP, Schwartz EG, Kalainov DM, Chen F, Makowiec RL. Complications of K-wire fixation in procedures involving wrist and hand. J Hand Surg Am 2011;36(4):610-6. Crossref

30. Tosti R, Foroohar A, Pizzutillo PD, Herman MJ. Kirschner wire infections in pediatric orthopaedic surgery: a 17-year experience. J Pediatr Orthop 2014;35(1):69-73. Crossref
31. Trousdale RT, Linscheid RL. Operative treatment of malunited fractures of the forearm. J Bone Joint Surg Am 1995;77(6):894-902. Crossref

32. Schwarz N, Pienaar S, Schwarz AF, Jelen M, Styhler W, Mayr J. Refracture of the forearm in children. J Bone Joint Surg Br 1996;78-B(5):740-4. Crossref

33. Cullen MC, Roy DR, Giza E, Crawford AH. Complications of intramedullary fixation of pediatric forearm fractures. J Pediatr Orthop 1998;18(1):14-21. Crossref

34. Vince KG, Miller JE. Cross-union complicating fracture of the forearm. Part I. adults. J Bone Joint Surg Am 1987;69(5):64053. Crossref 